either from her history (such as she could give) or physical examination, and all my tests were negative. I requested a domiciliary psychogeriatric consultation, and sweated blood over my referral letter. In return I got a charming letter, whose opening paragraph made me wish myself at the bottom of a very deep dark hole. It read:

'Dear Dr Lasserson, Thanks so much for asking me to see this interesting lady, and for your most helpful letter. I must say that my first impression was that she could well be hypothyroid and, indeed, her thyroid function tests confirm this ...'.

I fired off an immediate reply along the lines of 'Mea maxima culpa!' and the response was one of comforting reassurance together with the comment that 'we all miss these things...' and, of course, so we do. What made such an exchange easy was that I knew the consultant; we all knew our consultants, their strengths and their special interests, through the relationships we had slowly built up over the years through our direct referrals to them; something which, sadly, is no longer possible. As this has gone, so does it seem that there is no longer a place in our referrals for good concise English, itself another casualty of the box-ticking system; and so there is no longer room for individuality of style, for the occasional aphorism, the relevant quotation or, indeed, anything which makes a referral letter stand out as a personal document. Are we, I wonder, heading back to 'Dear Doctor, Please see and treat'?

\section{Michael Lasserson}

DOI: 10.3399/bjgp11X561447

\title{
Exhibition review
}

\section{SHINING LIGHTS EXHIBITION: THE STORY OF SCOTLAND'S LIGHTHOUSES \\ National Museum of Scotland, Edinburgh until 3 April 2011 www.nms.ac.uk/shininglights}

This exhibition marks the bicentenary of the lighting of the world's oldest rock lighthouse - the Bell Rock which lies 12 miles off Arbroath in the North Sea. The museum's collection of lighthouse-related objects was mainly assembled in the late 19th century and is a remarkable testament to some very special individuals who devoted themselves to saving lives by building and manning the lighthouses whose design and groundbreaking engineering achievements this exhibition celebrates.

The Stevenson family epitomised the values prevalent in much of Presbyterian Scotland in the late 18th and 19th centuries; a ferocious work ethic, loyalty to the cause of saving lives, and a respect for the sea which at times was sorely tested. Over four generations this family was responsible for the planning, designing and construction of 97 of the 208 lighthouses peppered round the Scottish coast. A map of their distribution seems to illustrate the utilitarian economy of scale which resulted in the optimum number for the greatest coverage of the thousands of miles of wild Scottish coastline, a possible metaphor for how to spread precious resources to minimise inequalities in the NHS ...

The variety of lenses and mirrors providing the power for the lights which ultimately guided the ships to safer waters were the result of cutting-edge technology excelled at by the French. One of the best known examples is the Fresnel lens, an awesome structure of sharp angles and beauty taking centre stage on the exhibition floor.

Alongside the science are the very human stories of the many keepers of the lights, the last of whom stepped down from his formidably rigorous duties in 1998 as the final remaining manned lighthouse was automated. Living as they had to in the most inhospitable corners of the country, their sacrifices are given prominence throughout the exhibition.

A suitable motto for this exhibition of blending cutting-edge science with human endeavour in the service of mankind would be Cum Scientia Caritas ... if you're in Edinburgh pop in and see it. It's free and very humbling.

\section{Murray Lough and Niall Cameron}

DOI: 10.3399/bjgp11X561456

\section{Rattray Head, between Peterhead and Fraserburgh, designed by David Alan Stevenson.}

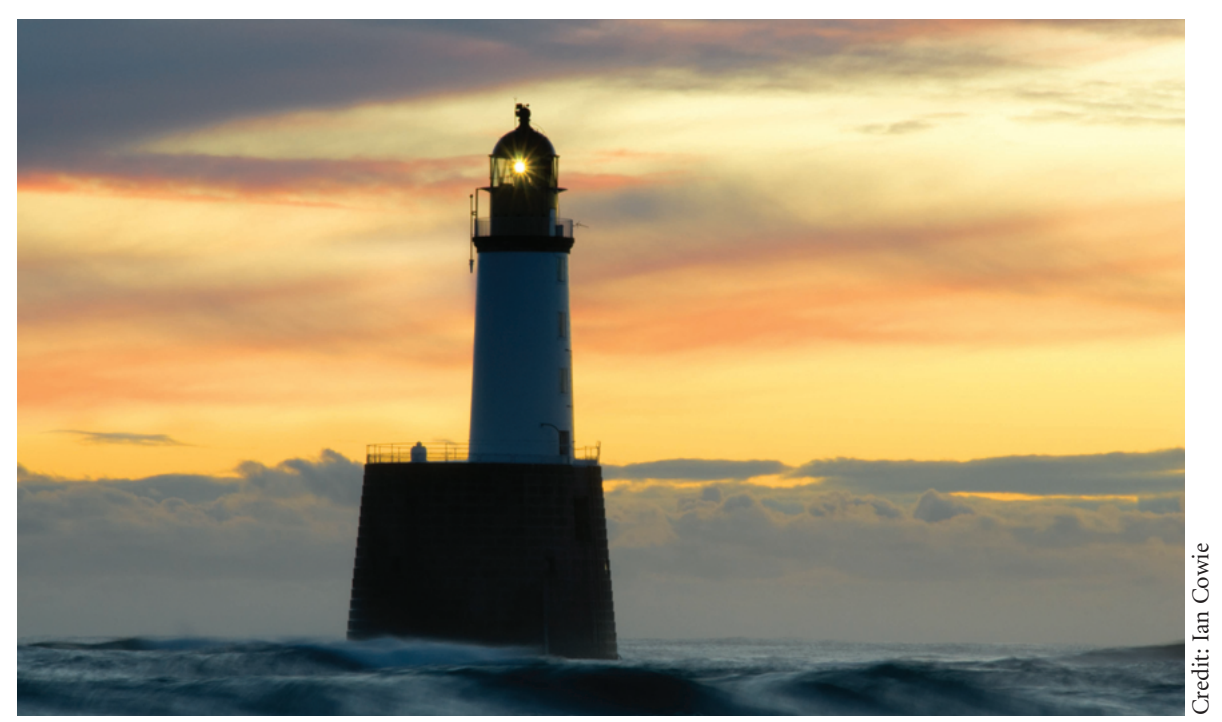

